Goldschmidt 2021 Abstract

https://doi.org/10.7185/gold2021.4460

\section{Biogeochemical heterogeneity in Palaeoarchaean microbial mats: a testament to the diversity and biological complexity of Earth's earliest ecosystems}

\section{KEYRON HICKMAN-LEWIS ${ }^{1}$, FRANCES WESTALL ${ }^{2}$ AND BARBARA CAVALAZZI ${ }^{3}$}

\author{
${ }^{1}$ The Natural History Museum \\ ${ }^{2}$ Centre de Biophysique Moléculaire, CNRS \\ ${ }^{3}$ Università di Bologna
}

Presenting Author: frances.westall@cnrs-orleans.fr

Fossilised microbial mats provide some of the oldest unambiguous evidence for life, dating to almost $3.5 \mathrm{Ga}$, and may be readily identified in numerous chert horizons [1-3]. Constraining microbial behaviour and metabolic networks within these widespread ecosystems is crucial for reconstructing the earliest biogeochemical networks within their specific palaeoenvironments.

Exceptionally preserved microbial mats from the Barberton greenstone belt (southern Africa) exhibit abundant evidence for microbial behaviour, including grain baffling and trapping, plastic lamina deformation and anastomosis. Mat-sediment interactions denote the presence of epibenthic and endobenthic communities [2]. X-ray computed micro-tomography (X-ray $\mu \mathrm{CT}$ ) shows that some mats exhibit micro-tufted 3D complexity, likely reflecting phototrophic growth [4]. Correlating mat fabrics with in situ palaeodepositional aqueous geochemistry acquired by LA ICP-MS shows that the oldest fossilised ecosystems flourished under chemically complex conditions, at the confluence of marine, riverine (continental) and hydrothermal inputs [3].

Fourier transform infra-red (FTIR) microspectroscopy of Palaeoarchaean mats shows that, despite dominantly aromatic carbon compositions, small amounts of carbonyl/carboxyl-group and aliphatic $\mathrm{CH}_{2}$ and $\mathrm{CH}_{3}$ moieties are preserved. Aliphatic moieties are interpreted as residues of original cellular components, specifically membrane lipids with relatively high preservation potential [5]. These earliest microbial ecosystems are characterised by $\mathrm{CH}_{3} / \mathrm{CH}_{2}$ intensity ratios between $\sim 0.1$ and $\sim 1.2$, consistent with origins in mixed bacterial (fatty acids) and archaeal (isoprenoid) membrane lipids. Statistically significant differences in spectral characteristics denote that some mats were dominated by Bacteria or Archaea, but most by mixed consortia [5]. Albeit at the domain level, these results present the first systematic taxonomic classification of Archaean microbial mats. Evidently, palaeoecology is applicable to even the oldest ecosystems.

In summary, our coupled biogeochemical studies demonstrate that Palaeoarchaean microbial biomes were diverse and complex and sustained a productive surface biosphere by $3.5 \mathrm{Ga}[c f .6]$. High-resolution correlative study of mat-bearing horizons can constrain the metabolic landscapes of the earliest microbial communities.
[1] Westall et al. (2015) Geology 43; [2] Hickman-Lewis et al. (2018) Precam. Res. 312; [3] Hickman-Lewis et al. (2020) Precam. Res. 342; [4] Hickman-Lewis et al. (2019) Geosciences 9; [5] Hickman-Lewis et al. (2018) Palaeontology 63; [6] Canfield et al. (2006) Phil. Trans. Roy. Soc. 361.
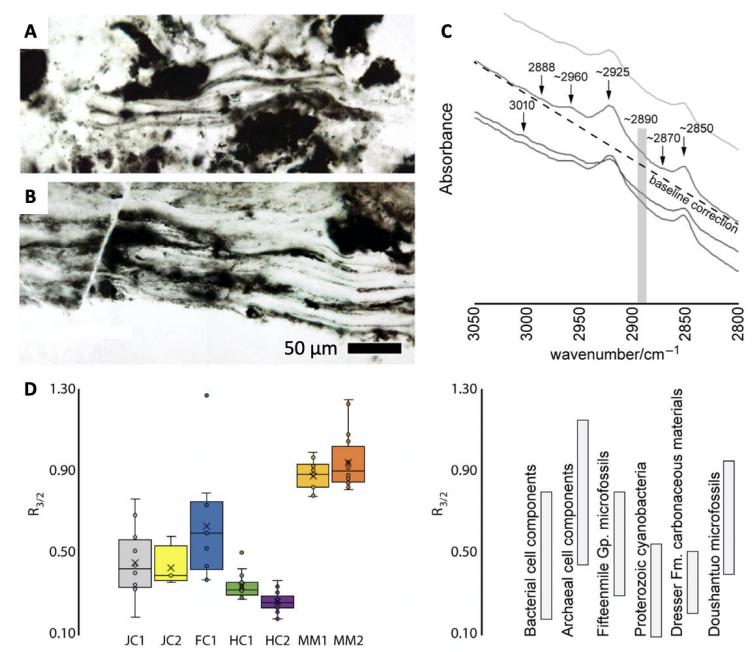

Fig. 1. A-B) Exceptionally preserved microbial mats from the 3.45 Ga Hooggenoeg Fm. C) FTIR spectra showing detections of aliphatic $\mathrm{C}-\mathrm{H}$ moieties. D) Taxonomic classification of Archaean = Footbridge Chert (both $3.33 \mathrm{Ga}$ ); $\mathrm{HC}=$ Hooggenoeg $\mathrm{Fm}$. MM = Middle Marker ( $3.472 \mathrm{Ga}$ ). 